\title{
Rectangular tank under the seismic load
}

\author{
Norbert Jendželovský1, ${ }^{1,}$ and Lenka Uhlířová ${ }^{1}$ \\ ${ }^{1}$ Faculty of Civil Engineering, STU in Bratislava, 81005 Bratislava, Slovak Republic
}

\begin{abstract}
Tanks have been currently used for the storage of various substances, in particular as drinking water storage tanks and for storage of various technical fluids. Rectangular tanks have advantages over cylindrical tanks, such as: lower sensitivity to unilateral loads and better use of space when used in a system of tanks. The rectangular tank analyzed in this article is filled with water. During the dynamic analysis of the tank, it was loaded by an accelerogram of a natural earthquake. In the calculation, the method of direct integration over time was used, considering damping. From the accelerogram a response spectrum was generated and applied as an additional loading of the tank. The static model of the tank was created in the ANSYS program, which works on the basis of the finite element method (FEM).
\end{abstract}

\section{Direct integration method}

The theoretical solution of the method of direct integration in time (step-by-step method) has been dealt with in [1]. This method consists in a procedure, when the behaviour of the system at the end of the time step has been derived from the conditions at the beginning of the same step. As the solution proceeds gradually in time steps, it is possible to consider the non-linear response of the structure. The time step is very small (hundredths to thousandths of a second) at which we must define the acceleration change in that time step. Accelerograms that are used to simulate an earthquake can be natural - obtained from an earthquake, or synthetic generated by programs to meet specified boundary conditions.

The dynamic analysis of tanks that are fixed or rested on an elastic subgrade has been mentioned e.g. in works [2-6], which inspired us in some details.

\section{Model}

The tank analyzed in this article is a rectangular, above-ground, reinforced concrete tank with a fixed bottom plate. The ground plan dimensions are $11.0 \mathrm{~m} \times 7.5 \mathrm{~m}$ and its height is $4.5 \mathrm{~m}$. The filling in the tank is water, its level reaches to a height of $4 \mathrm{~m}$, which limits the possibility of splashing under dynamic load. The static model of the tank made using the finite elements is shown in Fig. 1.

\footnotetext{
*Corresponding author: norbert.jendzelovsky@stuba.sk
} 


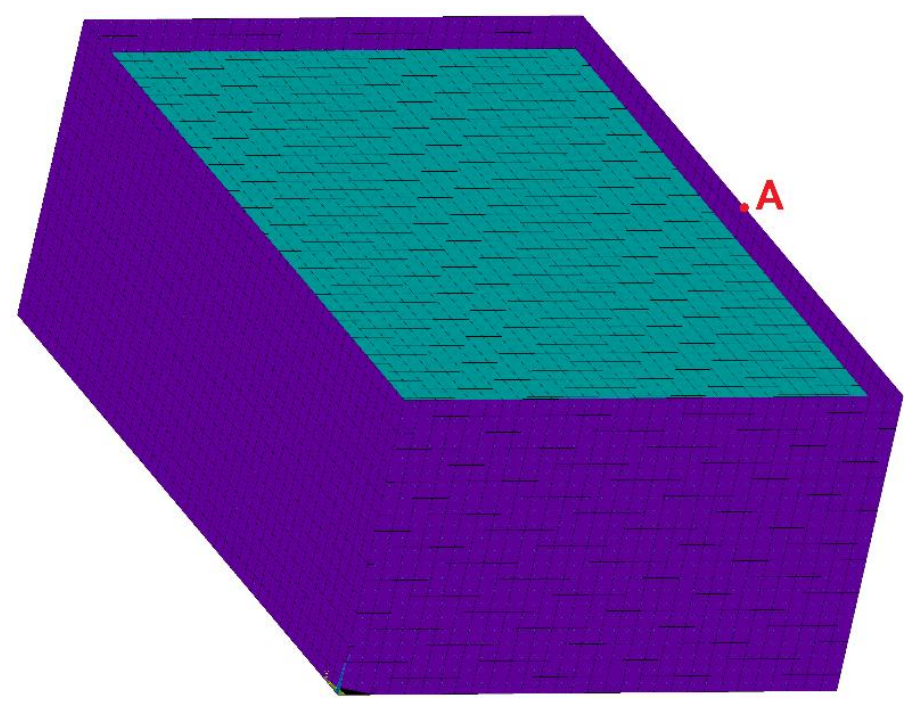

Fig. 1. FEM model of the tank.

The SHELL181 quadrilateral planar shell element was used in the ANSYS program for static modeling of tank walls with a thickness of $200 \mathrm{~mm}$ and tank bottom with a thickness of $500 \mathrm{~mm}$. The liquid 3D element FLUID80 was used for modeling water as a tank filling.

\section{The Accelerogram}

The input value for a dynamic calculation was the earthquake accelerogram (Fig. 2). Its time step is $0.01 \mathrm{~s}$.

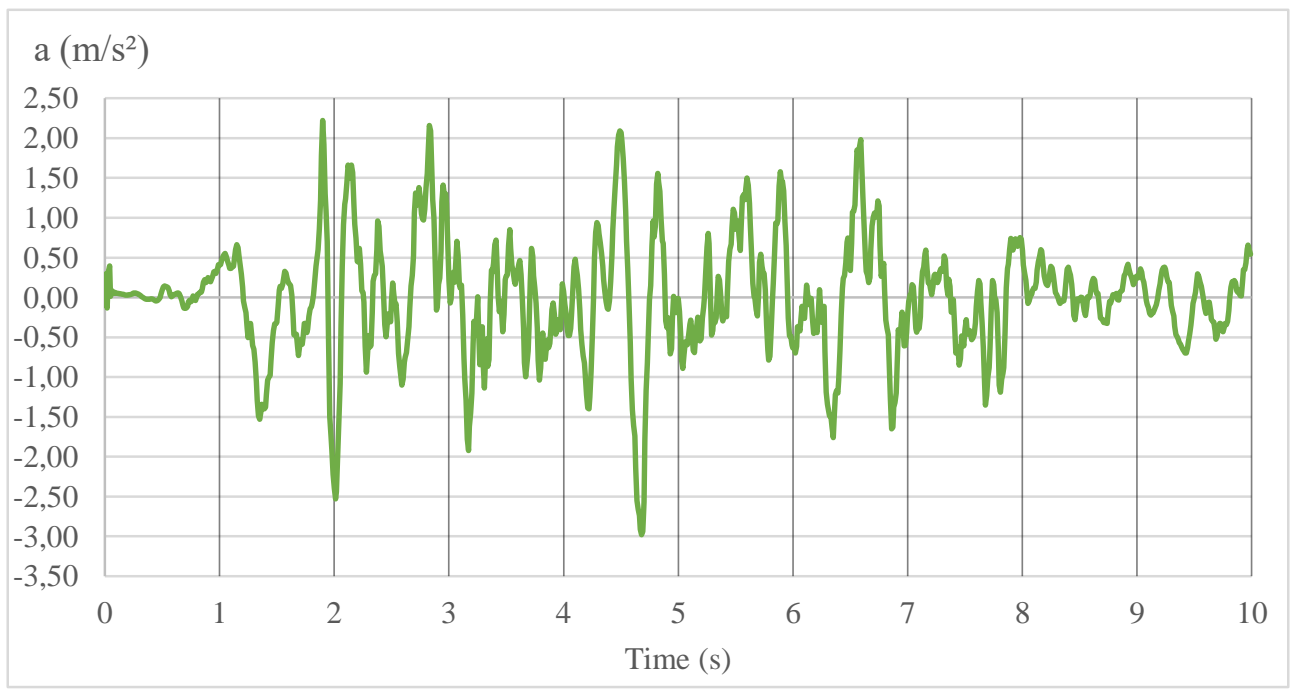

Fig. 2. Accelerogram of an applied earthquake (Varpalota, 1995, Hungary).

This accelerogram was imported into ANSYS software. We considered a $2 \%$ damping of the structure (recommended for reinforced concrete structures). The amount of damping was taken into account using Reyleigh damping (set values $\alpha=0.741525$ and $\beta=0.0005391$ ). 
In Fig. 3 there is a graph showing the horizontal displacement of one point in time. This point is located on the upper edge in the middle of the longer wall (point A in Fig. 1). In this point, the maximum displacement values have been reached.

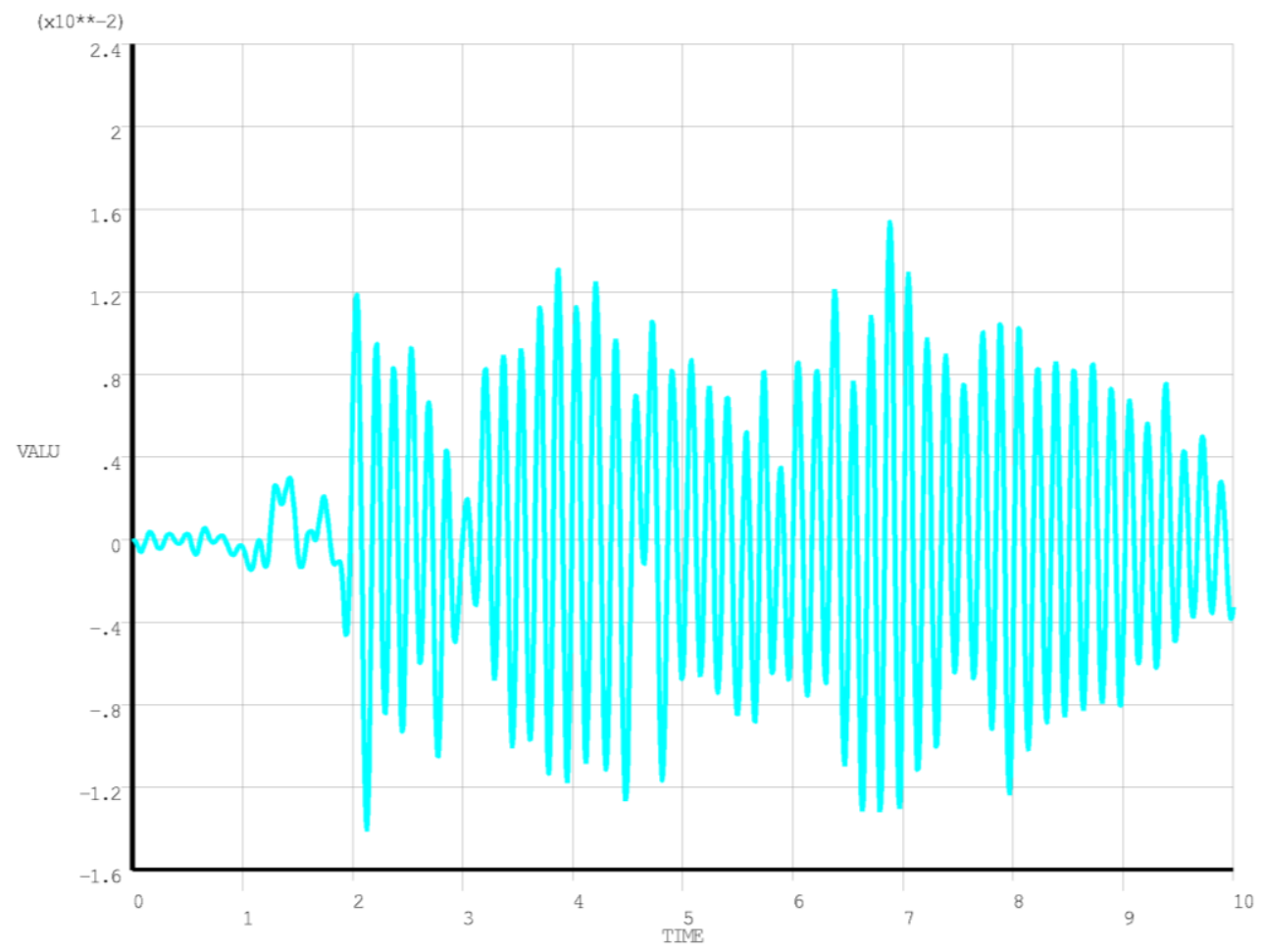

Fig. 3. Displacement of the point in the $x$-axis direction (m) in time (point A in Fig. 1).

The specific time $\mathrm{t}$ at which the displacement reached its highest value was $t=6.88 \mathrm{~s}$. At this time, the deformations of the tank were plotted in the $\mathrm{x}$-axis direction (Fig. 4) and in the $y$-axis direction (Fig. 5). The caption of the figure presents the maximum values of deformation of the tank walls.

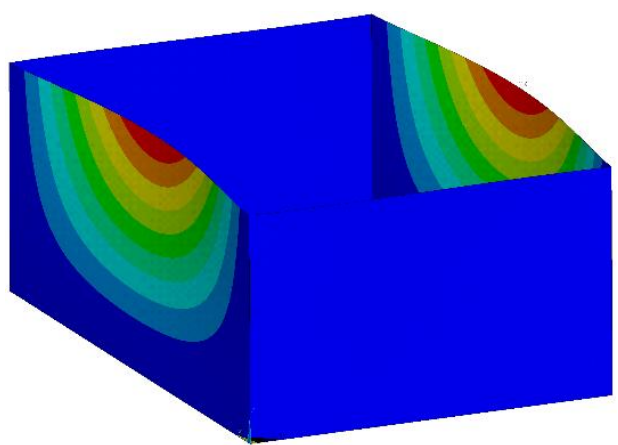

Fig. 4. Deformation in the $\mathrm{x}$-axis direction at time $6.88 \mathrm{~s}\left(u_{x}=15.429 \mathrm{~mm}\right)$.

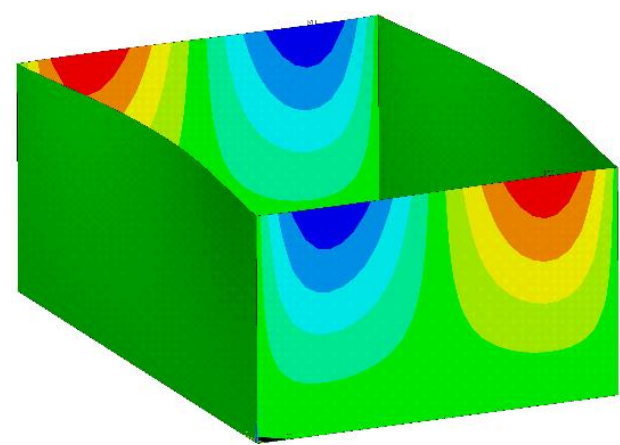

Fig. 5. Deformation in the $y$-axis direction at time $6.88 \mathrm{~s}\left(u_{y}=1.377 \mathrm{~mm}\right)$. 
The specific bending moments in the tank walls $m_{x}$ (Fig. 6) and $\mathrm{m}_{\mathrm{y}}$ (Fig. 7) at time $t=$ $6.88 \mathrm{~s}$ were also plotted on the structure.

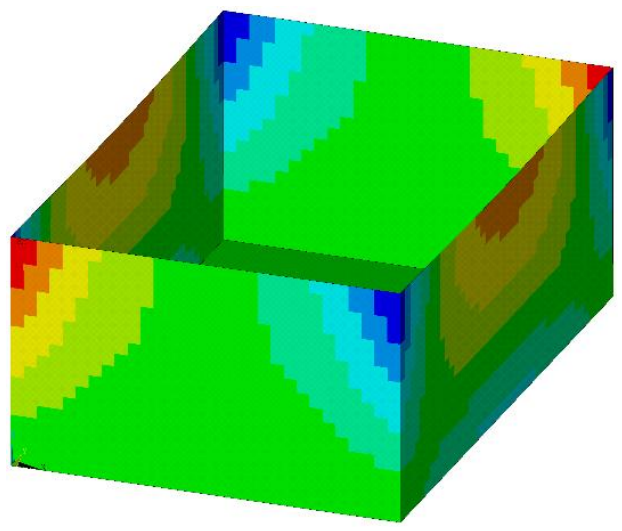

Fig. 6. Specific moment $m_{x}$ in the tank walls at time $6.88 \mathrm{~s}$ (maximum $m_{x}=46.004 \mathrm{kNm} / \mathrm{m}$ ).

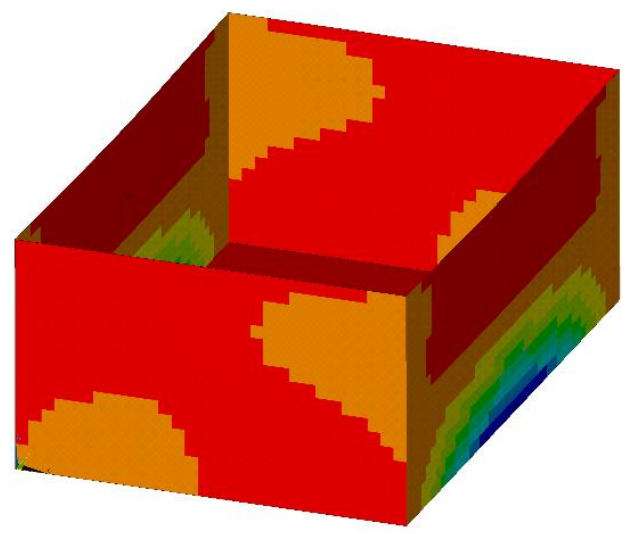

Fig. 7. Specific moment $m_{y}$ in the tank walls at time $6.88 \mathrm{~s}$ (maximum $m_{y}=46.004 \mathrm{kNm} / \mathrm{m}$ ).

Water at the investigated time $(t=6.88 \mathrm{~s})$ reached the largest deformation in the z-axis direction, with the wave size of $118.85 \mathrm{~mm}$ (Fig. 8). The water level at rest is $500 \mathrm{~mm}$ lower than the walls, so there is no risk of splashing out of the tank.

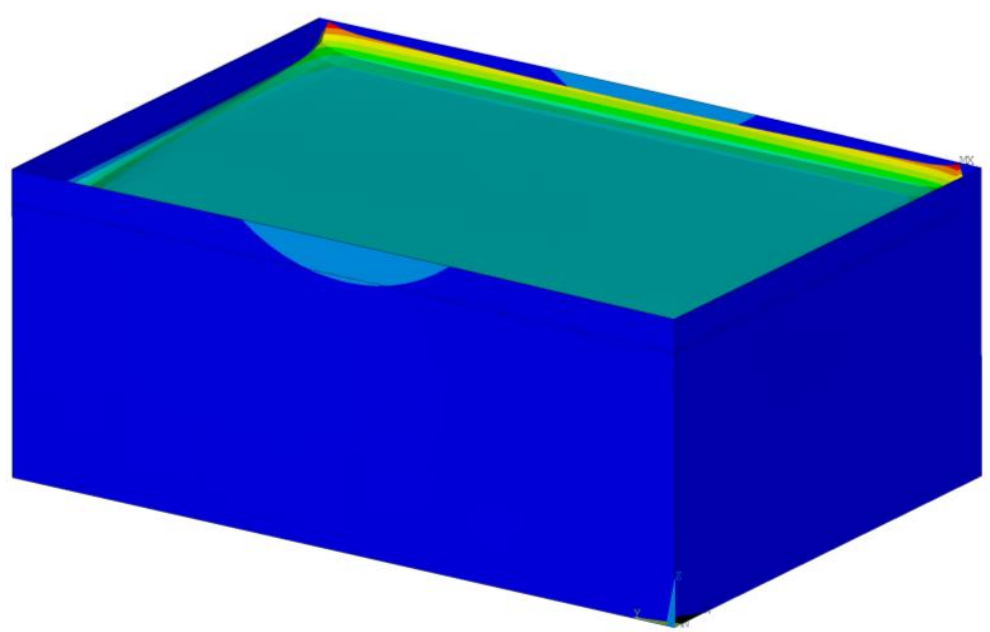

Fig. 8. Waving of the water surface in the tank at time $t=6.88 \mathrm{sec}$. due to earthquake effects $\left(u_{z}=\right.$ $118.85 \mathrm{~mm})$.

\section{The response spectrum}

To compare the results from the step-by-step method with the results obtained using the simpler spectral method, the response spectrum from the used accelerogram was created. This spectrum was generated by means of a subroutine in the RFEM Dlubal calculation software and recalculated for different number of time steps. From these courses an envelope - response spectrum was created, by which the tank was loaded (Fig. 9). 


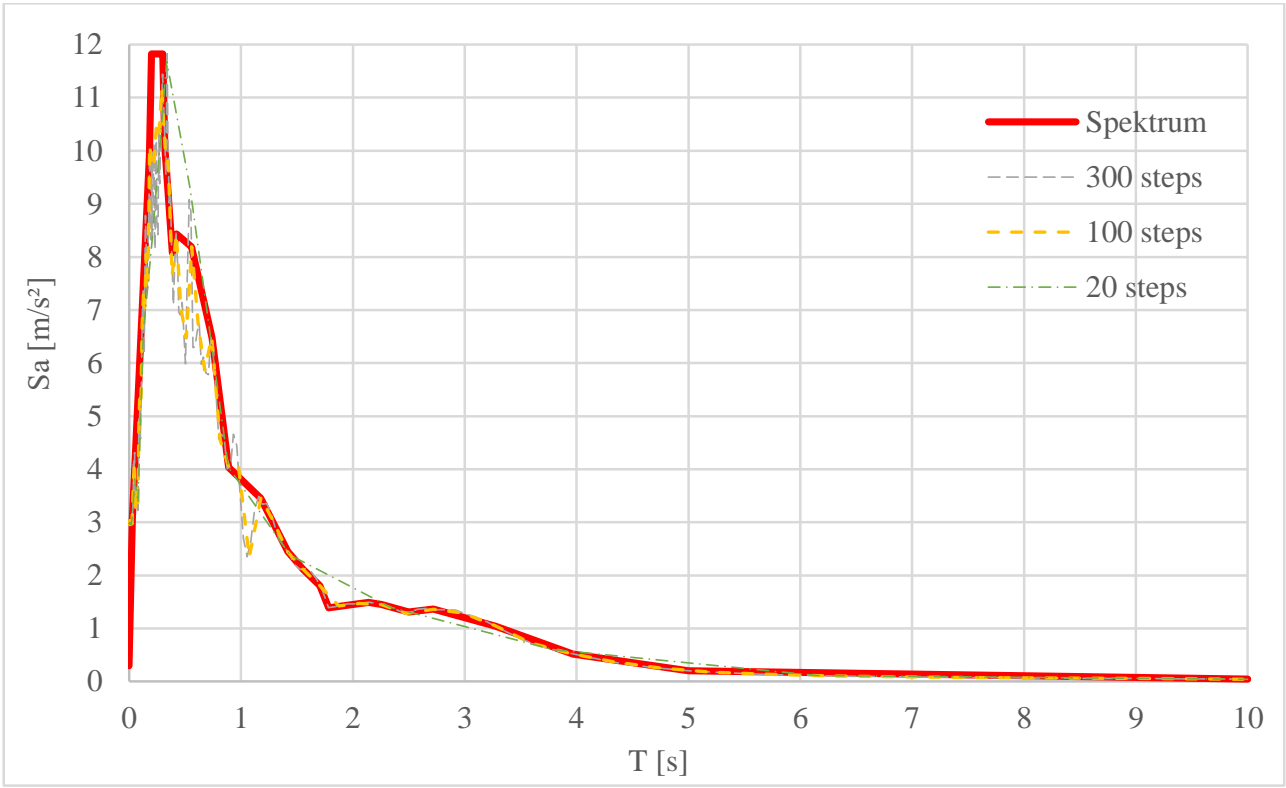

Fig. 9. Response spectrum obtained from accelerogram (Fig. 2) with $2 \%$ damping.

From the results obtained on the structure of the tank loaded by the response spectrum, see Fig. 9, we present the values of maximum tank wall deformations $u_{x}$ (Fig. 10) and $u_{y}$ (Fig. 11). The maximum reached values have been mentioned in captions of the figures.

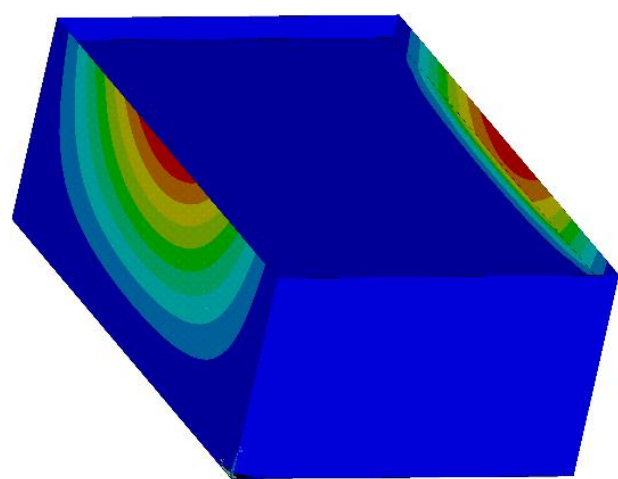

Fig. 10. Deformation in the $x$-axis direction $\left(u_{x}=16.839 \mathrm{~mm}\right)$.

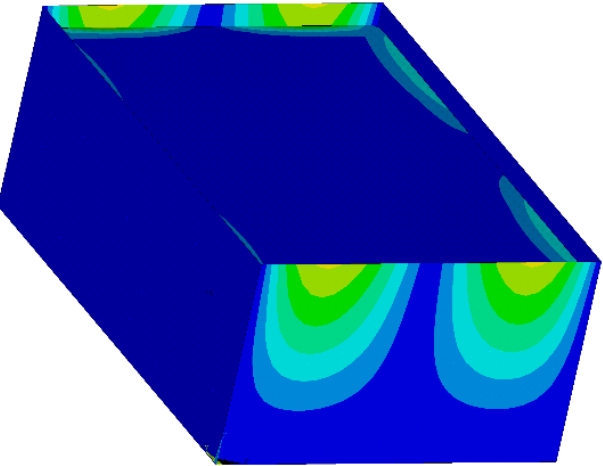

Fig. 11. Deformation in the y-axis direction $\left(u_{y}=2.217 \mathrm{~mm}\right)$.

The specific bending moments in the tank walls $m_{x}$ (Fig. 12) and $m_{\mathrm{y}}$ (Fig. 13) were also plotted on the structure. 


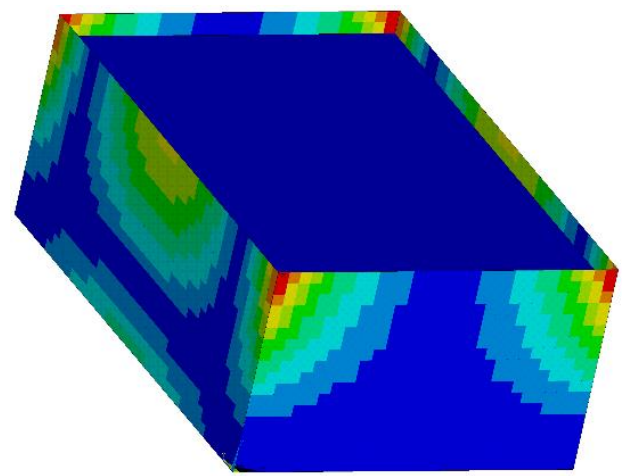

Fig. 12. Specific moment $m_{x}$ in the tank walls (maximum $m_{x}=51.054 \mathrm{kNm} / \mathrm{m}$ ).

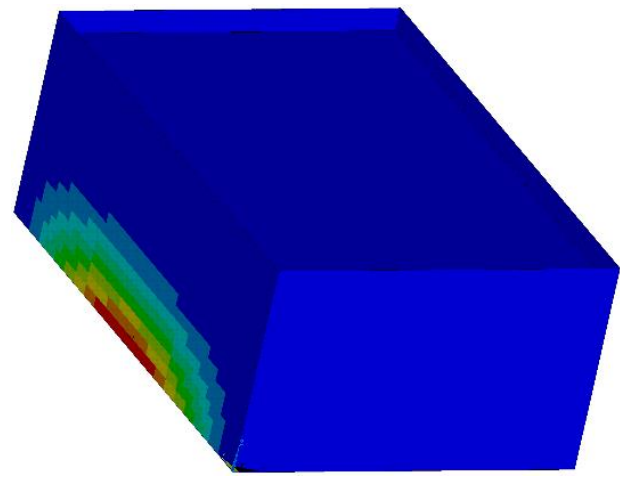

Fig. 13. Specific moment $m_{y}$ in the tank walls (maximum $m_{y}=90.651 \mathrm{kNm} / \mathrm{m}$ ).

\section{Comparison of results}

As it can be seen in Table 1, when applying the accelerogram loading and response spectrum loading (obtained from the given accelerogram), there is a difference in both the resulting deformations and the specific moments in the walls. The values obtained by spectral analysis are higher. This confirms the correctness of both calculations since the results obtained from the response spectrum should be higher than those obtained by direct integration over time.

Table 1. Comparison of deformations and specific moments during an earthquake with $2 \%$ damping.

\begin{tabular}{|c|c|c|}
\hline & Accelerogram & Spectrum \\
\hline $\boldsymbol{u}_{\boldsymbol{x}}[\mathbf{m m}]$ & 15.429 & 16.839 \\
\hline $\boldsymbol{u}_{\boldsymbol{y}}[\mathbf{m m}]$ & 1.377 & 2.217 \\
\hline $\boldsymbol{m}_{\boldsymbol{x}}[\mathbf{k N m} / \mathbf{m}]$ & 46.004 & 51.054 \\
\hline $\boldsymbol{m}_{\boldsymbol{y}}[\mathbf{k N m} / \mathbf{m}]$ & 87.527 & 90.651 \\
\hline
\end{tabular}

This paper was written with the support of Slovak Grant Agency VEGA 1/0412/18, and KEGA $025 \mathrm{STU}-4 / 2019$. 


\section{References}

1. M. Sokol, K. Tvrdá, Dynamika stavebných konštrukcií (Bratislava, STU v Bratislave 2011)

2. K. Kotrasová, E. Kormaníková, A case study on seismic behavior of rectangular tanks considering fluid Structure interaction. International Journal of Mechanics, 10, 242-252 (2016)

3. K. Kotrasová, I. S. Leoveanu, E. Kormaníková, A comparative study of the seismic analysis of rectangular tanks according to EC8 and IS 1893. Buletinul AGIR, 18, 3, 120 125 (2013)

4. K. Kotrasová, E. Kormaníková, Hydrodynamic analysis of fluid effect in rigid rectangular tank due to harmonic motion, 9th International Conference on Material in Engineering Practice 2014, Herlany, Slovakia, (2014)

5. J. Kala, V. Salajka, P. Hradil, Response of water tower on wind induced vibration considering interaction of fluid and structure. 2nd International Conference on Engineering and Technology Innovation, Taiwan, pp. 1269-1272 (2012)

6. R. Cajka, P. Mynarcik, J. Labudkova, Numerical solution of soil-foundation interaction and comparison of results with experimental measurements. International Journal of GEOMATE, 11, 2116-2122 (2016) 